\title{
Counterflow heat exchanger with core and plenums at both ends
}

A. Bejan ${ }^{1}$, M. Alalaimi ${ }^{1}$, S. Lorente ${ }^{2}$, A.S. Sabau ${ }^{3}$, J. W. Klett ${ }^{3}$

${ }^{1}$ Duke University,Durham, NC 27708-0300, U.S.A

${ }^{2}$ Université de Toulouse, INSA, 135 Avenue de Rangueil,31077 Toulouse, France

${ }^{3}$ Oak Ridge National Laboratory, Oak Ridge, TN 37830, USA

"Corresponding author, abejan@duke.edu

Abstract

This paper illustrates the morphing of flow architecture toward greater performance in a counterflow heat exchanger. The architecture consists of two plenums with a core of counterflow channels between them. Each stream enters one plenum and then flows in a channel that travels the core and crosses the second plenum. The volume of the heat exchanger is fixed while the volume fraction occupied by each plenum is variable. Performance is driven by two objectives, simultaneously: low flow resistance and low thermal resistance. The analytical and numerical results show that the overall flow resistance is the lowest when the core is absent, and each plenum occupies half of the available volume and is oriented in counterflow with the other plenum. In this configuration, the thermal resistance also reaches its lowest value. These conclusions hold for fully developed laminar flow and turbulent flow through the core. The curve for effectiveness vs number of heat transfer units $\left(\mathrm{N}_{\mathrm{tu}}\right)$ is steeper (when $\mathrm{N}_{\mathrm{tu}}<1$ ) than the classical curves for counterflow and crossflow.

Keywords: Constructal, heat exchanger, counterflow, crossflow, morphing. 


\section{Nomenclature}

A area, $\mathrm{m}^{2}$

C capacity rate, $\mathrm{W} / \mathrm{K}$

$\mathrm{C}_{\mathrm{D}} \quad$ drag coefficient

$\mathrm{C}_{\mathrm{th}}$ thermal conductance, $\mathrm{W} / \mathrm{K}$

D diameter, $\mathrm{m}$

F force, $\mathrm{N}$

f friction factor

$\mathrm{H}$ height, $\mathrm{m}$

h heat transfer coefficient, $W / \mathrm{m}^{2} \mathrm{~K}$

$\mathrm{K}_{1} \quad$ factor, $\mathrm{m}^{2} / \mathrm{s}$, Eq. (3)

$\mathrm{K}_{\mathrm{t}} \quad$ factor, $\mathrm{m}^{3} / \mathrm{kg}$, Eq. (8)

L length, $\mathrm{m}$

$\dot{\mathrm{m}}$ mass flow rate, $\mathrm{kg} / \mathrm{s}$

n number of tubes

$\mathrm{N}_{\mathrm{tu}} \quad$ number of heat transfer units

q heat transfer, W

$\mathrm{R}_{\mathrm{f}} \quad$ fluid flow resistance

$\mathrm{R}_{\text {th }} \quad$ thermal resistance

Re Reynolds number

T cold temperature, $\mathrm{K}$

$\mathrm{U} \quad$ overall heat transfer coefficient, $\mathrm{W} / \mathrm{m}^{2} . \mathrm{K}$

$\mathrm{U}_{\mathrm{c}} \quad$ core fluid velocity, $\mathrm{m} / \mathrm{s}$ 


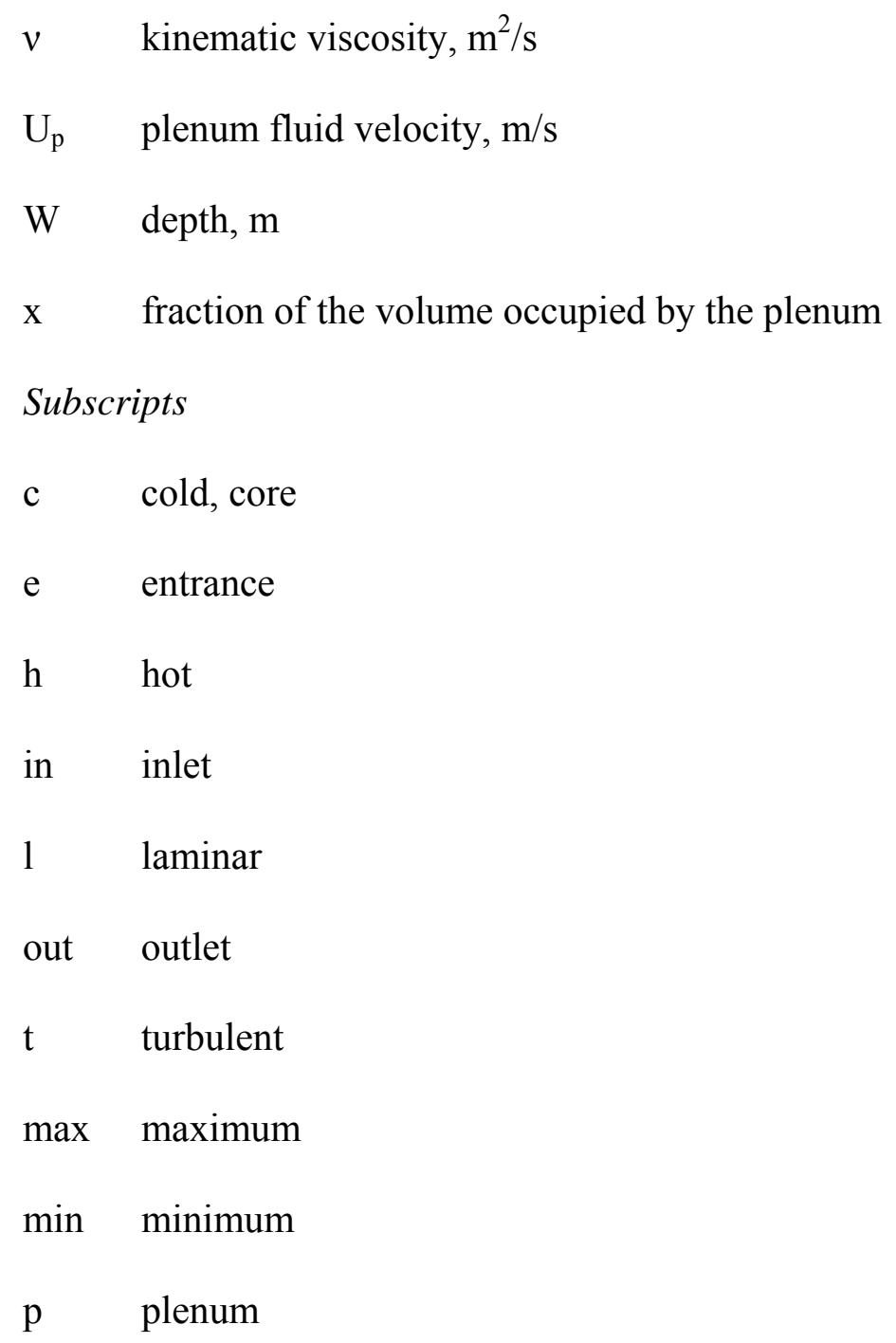

\section{Introduction}

Heat exchangers are a central topic in thermal science and engineering because of their essential role across the landscape of technology, from geothermal and fossil power generation to refrigeration, desalination, and air conditioning [1-4]. The literature on heat exchangers is 
voluminous andcontinues to be active today (e.g., Refs. 5-10). The field covers two main aspects of this class of flow systems: fluid flow and heat transfer performance, and ways (criteria) of evaluating performance [11-15].The general trend in the field is to develop heat exchangers that offer better performance. This trend is universal in evolution [16], and unites heat exchangers with other evolutionary flow systems, bio, non bio, and manmade.

The starting point for the present paper is the observation that all performance criteria change, and hopefully improve, when one changes and chooses a better flowing architecture. This, the free evolution of the flow architecture is captured by the law of physics of evolution [17]: it is the essence of constructal design [18], and serves as unifying method for all evolutionary design phenomena. Here, we illustrate this approach by analyzing a morphing twostream counterflow heat exchanger with one plenum at each end. The key architectural feature to be discovered is how much of the total volume is allocated to the counterflow core and the plenums.

\section{Model}

Two streams $\left(\dot{\mathrm{m}}_{1}, \dot{\mathrm{m}}_{2}\right)$ flow in counterflow through parallel tubes of diameter $\mathrm{D}$, in a core situated between two plenums. As shown in Fig. 1, eachstream arrives into a plenum (xL) by flowing across tubes that carry the second stream. At the other end, the second stream arrives into a plenum by flowing across tubes that carry the first stream.

The elemental volume of the heat exchanger has the longitudinal length $\mathrm{L}$ (one plenum + the flow length of one stream) and the width $\mathrm{H}=\mathrm{nD}$, shown in the vertical direction in Fig. 1. The third dimension of this element is $\mathrm{D}$, and is not shown in Fig. 1. The number of $\mathrm{H} \times \mathrm{L}$ elements stacked in the third dimension is not important. The size of the element is dictated by the area A $=\mathrm{HL}$, which is fixed, and the tube diameter, which is also fixed. 
The challenge is to determine the most effective configuration, which is represented by the shape parameter $(\mathrm{H} / \mathrm{L})$ and the volume fraction occupied by one plenum $(\mathrm{x})$. The element has two functions, flow with low pressure drop along each stream, and low thermal resistance between the streams.

\section{Pressure drop}

The overall pressure drop experienced by one stream $\dot{\mathrm{m}}_{1}$ is due to contributions from the plenum (p) and the core flow (c), through tubes of diameter D and length $(1-\mathrm{x}) \mathrm{L}$,

$$
\Delta \mathrm{P}=\Delta \mathrm{P}_{\mathrm{p}}+\Delta \mathrm{P}_{\mathrm{c}}
$$

The plenum has the flow cross section $x L D$, flow length $H$ (vertical in Fig. 1), and average fluid velocity $U_{p}=\dot{m}_{1} /(\rho x L D)$. The drag force experienced by each tube of length $x L$ (or frontal

area $x L D$ ) inside the plenum is $F_{1}=C_{D} \times L D \frac{1}{2} \rho U_{p}^{2}$, where we regard $C_{D}$ as of order 1 , based on the assumption that the Reynolds number based on $\mathrm{D}$ inside the plenum is greater than $10^{2}$. From the vertical force balance on the plenum, $\Delta \mathrm{P}_{\mathrm{p}} \times \mathrm{LD}=\mathrm{nF}_{1}$, we deduce

$$
\Delta \mathrm{P}_{\mathrm{p}}=\frac{\mathrm{n} \dot{\mathrm{m}}_{1}^{2}}{2 \rho(\mathrm{x} \mathrm{LD})^{2}}
$$

For the in-tube flow, we start with the assumption that the flow is in the fully developed laminar regime. The mass flow rate through one tube is $\dot{\mathrm{m}}_{1} / \mathrm{n}$. The pressure drop along the duct of length $(1-\mathrm{x}) \mathrm{L}$ is

$$
\Delta \mathrm{P}_{\mathrm{c}}=\mathrm{K}_{1} \frac{\dot{\mathrm{m}}_{1}}{\mathrm{n}} \frac{(1-\mathrm{x}) \mathrm{L}}{\mathrm{D}^{4}}
$$

whereK $_{1}=128 v / \pi$. Next, we combine Eqs. (1) $-(3)$, replace $n$ with $H / D$, and then replace $H$ with A/L. The resulting expression for the overall pressure drop is 


$$
\Delta \mathrm{P}=\frac{\mathrm{Am}_{1}^{2}}{2 \rho \mathrm{D}^{3} \mathrm{x}^{2} \mathrm{~L}^{3}}+\mathrm{K}_{1} \dot{\mathrm{m}}_{1} \frac{(1-\mathrm{x}) \mathrm{L}^{2}}{\mathrm{AD}^{3}}
$$

This expression reaches its minimum when $\mathrm{L}$ is of order

$$
L_{o p t}=\left[\frac{3 A^{2} \dot{m}_{1}}{4 K_{1} \rho x^{2}(1-x)}\right]^{1 / 5}
$$

From this follows $\mathrm{H}_{\mathrm{opt}}=\mathrm{A} / \mathrm{L}_{\mathrm{opt}}$, the optimal shape of the assembly,

$$
\left(\frac{\mathrm{H}}{\mathrm{L}}\right)_{\mathrm{opt}}=\mathrm{A}\left[\frac{4 \mathrm{~K}_{1} \rho \mathrm{x}^{2}(1-\mathrm{x})}{3 \mathrm{~A}^{2} \dot{\mathrm{m}}_{1}}\right]^{2 / 5}
$$

and the pressure drop minimized by selecting the shape of A,

$$
\Delta \mathrm{P}_{\min }=\frac{5}{3^{3 / 5} 4^{2 / 5}} \mathrm{~K}_{1}^{3 / 5} \dot{\mathrm{m}}_{1}^{7 / 5} \mathrm{~A}^{-1 / 5} \mathrm{D}^{-3} \rho^{-2 / 5} \frac{(1-\mathrm{x})^{3 / 5}}{\mathrm{x}^{4 / 5}}
$$

First, note the effect of size (A) on performance $\left(\Delta \mathrm{P}_{\min }\right)$. The performance improves monotonically as the size increases. This result is in accord with theoretical advances on the effect of size on efficiency in thermofluid flow systems in general $[17,19]$.

Second, the effect of dividing the elemental volume into plenum $(\mathrm{x})$ and in-tube flow $(1-\mathrm{x})$ is such that $\Delta \mathrm{P}_{\min }$ decreases monotonically as $\mathrm{x}$ increases. The lowest pressure drop belongs to the design with $\mathrm{x}=0.5$, which is the design without a counterflow core, and with two plenums each of thickness $\mathrm{x}=1 / 2$, or $\mathrm{L} / 2$. This design is sketched in Fig. 2 .

The preceding analysis can be repeated by assuming that in the core tubes the flow is in the fully developed fully rough turbulent regime ( $\mathrm{f}=$ constant), when Eq. (3) is replaced by

$$
\Delta \mathrm{P}_{\mathrm{c}}=\mathrm{K}_{\mathrm{t}}\left(\frac{\dot{\mathrm{m}}_{1}}{\mathrm{n}}\right)^{2} \frac{\mathrm{L}(1-\mathrm{x})}{\mathrm{D}^{5}}
$$

where $K_{t}=32 f /\left(\pi^{2} \rho\right)$. Equation (2) does not change. In place of Eqs. (3) - (7) we obtain 


$$
\begin{gathered}
\Delta \mathrm{P}_{\mathrm{c}}=\mathrm{K}_{\mathrm{t}} \dot{\mathrm{m}}_{1}^{2} \frac{\mathrm{L}^{3}(1-\mathrm{x})}{\mathrm{D}^{3} \mathrm{~A}^{2}} \\
\mathrm{~L}_{\mathrm{opt}}=\left[\frac{\mathrm{A}^{3}}{2 \rho \mathrm{K}_{\mathrm{t}} \mathrm{x}^{2}(1-\mathrm{x})}\right]^{1 / 6} \\
\left(\frac{\mathrm{H}}{\mathrm{L}}\right)_{\mathrm{opt}}=\left[2 \rho \mathrm{K}_{\mathrm{t}} \mathrm{x}^{2}(1-\mathrm{x})\right]^{1 / 3} \\
\Delta \mathrm{P}_{\min }=\left(2 \mathrm{~K}_{\mathrm{t}} / \rho \mathrm{A}\right)^{1 / 2} \frac{\dot{\mathrm{m}}_{1}^{2}(1-\mathrm{x})^{1 / 2}}{\mathrm{D}^{3} \mathrm{x}}
\end{gathered}
$$

The results for turbulent core flow, Eqs. (10) - (12), show qualitatively the same trends as the results for laminar core flow, Eqs. (5) - (7). The conclusion is the same as before: the overall pressure drop decreases monotonically as $\mathrm{x}$ increases up to $1 / 2$, and the core vanishes.

\section{Thermal conductance}

The thermal contact between the two streams in Fig. 1 is proportional to the overall thermal conductance

$$
\mathrm{C}_{\text {th }} \sim \mathrm{A}_{\mathrm{p}} \mathrm{h}_{\mathrm{p}, \text { tot }}+\mathrm{A}_{\mathrm{c}} \mathrm{h}_{\mathrm{c}, \text { tot }}
$$

whereh $h_{p, t}$ and $h_{c, t}$ are the overall heat transfer coefficients including htc on both sides of the tubes and conduction through the tube. $\mathrm{A}_{\mathrm{p}}$ and $\mathrm{A}_{\mathrm{c}}$ are the contact surfaces in the plenum and the core,

$$
\mathrm{A}_{\mathrm{p}} \sim \mathrm{nxLD}, \quad \mathrm{A}_{\mathrm{c}} \sim \mathrm{n}(1-\mathrm{x}) \mathrm{LD}
$$

orusing $\mathrm{H} \sim \mathrm{nD}$ :

$$
A_{p} \sim \mathrm{HxL}, \quad \mathrm{A}_{\mathrm{c}} \sim \mathrm{H}(1-\mathrm{x}) \mathrm{L}
$$

wheren is the number of tubes in cross flow in each plenum, and $h_{p}$ and $h_{c}$ are the respective scales (orders of magnitude) of the heat transfer coefficients (to read more on scale analysis and 
the nature of trade offs in design, see Refs. 20-22). Noting that in an order of magnitude sense $\mathrm{H}$ $\sim \mathrm{nD}$, we replace $\mathrm{n}$ with $\mathrm{H}$ in Eq. (13) and rewrite it as:

$$
\frac{\mathrm{C}_{\mathrm{th}}}{\mathrm{A}} \sim \mathrm{h}_{\mathrm{p}}+(1-\mathrm{x}) \mathrm{h}_{\mathrm{c}}
$$

where $A=H L$. The order of magnitude of $h_{p}$ can be estimated as shown in Eq. (17) and the Appendix. Reading Eq. (16), we distinguish two cases:

(i) If $h_{p}>h_{c}$, then the $x=1 / 2$ design of Fig. 2 is also the design with the highest thermal conductance.

(ii) If $h_{c}>h_{p}$, then the highest thermal conductance occurs in the limit $\mathrm{x}=0$, which coincides with the worst design for pressure drop. This domain, $h_{c}>h_{p}$, is where $x$ will be assigned an intermediate value, as a trade off between a low enough $\Delta \mathrm{P}$ and a high enough $\mathrm{C}_{\mathrm{th}}$.

In the plenum, the heat transfer is impeded by three thermal resistances, on the outside of the tube, the tube wall, and inside the tube. The tube wall resistance is negligible (cf. Appendix), and the convective resistance on the outer surface of the tube dominates the convective resistance on the inside surface when the $h_{p} / h_{c, t}$ ratio derived later in Eq. (23) for turbulent flow is less than $1 \mathrm{in}$ an order of magnitude sense. This is the case in the present analysis, therefore the overall heat transfer coefficient scale for the plenum is represented by the outer heat transfer coefficient, $h_{p}$. The order of magnitude of $h_{p}$ is estimated from the Nusselt number for a single tube in cross flow, cf. Eq. (7.100) in Ref. 20, where $h_{p} D / k \sim 0.6 \operatorname{Re}_{p}^{1 / 2}$ if $\operatorname{Re}_{p}=U_{p} D / v>>1$, and $\operatorname{Pr} \sim 1$ :

$$
\mathrm{h}_{\mathrm{p}} \sim 0.6 \mathrm{k}\left(\frac{\mathrm{U}_{\mathrm{p}}}{v \mathrm{D}}\right)^{1 / 2}
$$

If the flow through the core is laminar and fully developed, then the in-duct Nusselt number is a constant of order 4, and the heat transfer coefficient is of order 


$$
\mathrm{h}_{\mathrm{c}, 1} \sim 4 \frac{\mathrm{k}}{\mathrm{D}}
$$

Dividing Eqs. (17) and (18), we obtain

$$
\frac{\mathrm{h}_{\mathrm{p}}}{\mathrm{h}_{\mathrm{c}, 1}} \sim 0.15 \mathrm{Re}_{\mathrm{p}}^{1 / 2}
$$

which is a ratio greater than 1 when $\operatorname{Re}_{\mathrm{p}}>10^{2}$, that is when the flow downstream of the cylinder in cross flow is turbulent. This situation corresponds to case (i).

If the flow through the core is turbulent and fully developed, then, according to Eq. (8.30) in Ref. $20, \mathrm{~h}_{\mathrm{c}, \mathrm{t}} \mathrm{D} / \mathrm{k} \sim 0.023 \mathrm{Re}_{\mathrm{c}}^{4 / 5}$ where $\operatorname{Re}_{\mathrm{c}}=\mathrm{U}_{\mathrm{c}} \mathrm{D} / \mathrm{v}$, therefore

$$
\mathrm{h}_{\mathrm{c}, \mathrm{t}} \sim 0.023 \frac{\mathrm{k}}{\mathrm{D}}\left(\frac{\mathrm{U}_{\mathrm{c}} \mathrm{D}}{\mathrm{v}}\right)^{4 / 5}
$$

Dividing Eqs. (17) and (20) we obtain

$$
\frac{\mathrm{h}_{\mathrm{p}}}{\mathrm{h}_{\mathrm{c}, \mathrm{t}}} \sim 26 \frac{\mathrm{Re}_{\mathrm{p}}^{1 / 2}}{\mathrm{Re}_{\mathrm{c}}^{4 / 5}}
$$

Because of $U_{p}=\dot{m}_{1} /(\rho x L D)$ and $U_{c}=\left(\dot{m}_{1} / n\right) /\left(\rho \frac{\pi}{4} D^{2}\right)$, we rely on the proportionality

$$
\frac{\mathrm{U}_{\mathrm{p}}}{\mathrm{U}_{\mathrm{c}}}=\frac{\pi}{4} \frac{\mathrm{H}}{\mathrm{xL}}
$$

to rewrite Eq. (21) as

$$
\frac{h_{p}}{h_{c, t}} \sim 22 \operatorname{Re}_{p}^{-3 / 10}\left(\frac{H}{x L}\right)^{4 / 5}
$$

From this follows the rewriting of Eq. (16), 


$$
\begin{aligned}
\frac{\mathrm{C}_{\mathrm{th}}}{\mathrm{HL}} & \sim \mathrm{h}_{\mathrm{p}}\left[1+(1-\mathrm{x}) \frac{\mathrm{h}_{\mathrm{c}, \mathrm{t}}}{\mathrm{h}_{\mathrm{p}}}\right] \\
& \sim \mathrm{h}_{\mathrm{p}}\left[1+(1-\mathrm{x}) \frac{\operatorname{Re}_{\mathrm{p}}^{3 / 10}}{22}\left(\frac{\mathrm{H}}{\mathrm{xL}}\right)^{-4 / 5}\right]
\end{aligned}
$$

In summary, there are two flow resistances, fluid $R_{f}$ and thermal $R_{t h}$, which are defined next. At this point, the analysis can proceed on two routes: select the area shape $\mathrm{H} / \mathrm{L}$ by minimizing the flow resistance, e.g. Eq. (11), or select $\mathrm{H} / \mathrm{L}$ by minimizing the thermal resistance. Consider the first route, for which Eq. (11) shows that $\mathrm{H} / \mathrm{L}$ is proportional to $\left[\mathrm{x}^{2}(1-\mathrm{x})\right]^{1 / 3}$. The second term in the square brackets of Eq. (24) is proportional to $(1-\mathrm{x})^{11 / 15} \mathrm{x}^{2 / 3}$, and is maximum at $\mathrm{x}=$ 10/21. This means that the highest thermal conductance belongs to a design with approximately $\mathrm{x}=1 / 2$, which is the design with lowest pressure drop.

The trade off between flow resistance and thermal resistance is illustrated qualitatively by the right curve in Fig. 3. For turbulent flow in the core, Eq. (12) shows that the flow resistance varies in proportion with the group

$$
\mathrm{R}_{\mathrm{f}}=\frac{1}{\mathrm{x}}(1-\mathrm{x})^{1 / 2}
$$

The overall thermal conductance, Eq. (24), increases monotonically with $(1-x)^{11 / 15} x^{2 / 3}$, therefore the overall thermal resistance varies monotonically (not proportionally) with

$$
\mathrm{R}_{\mathrm{th}}=(1-\mathrm{x})^{-11 / 15} \mathrm{x}^{-2 / 3}
$$

$\mathrm{R}_{\mathrm{f}}$ and $\mathrm{R}_{\mathrm{th}}$ are related parametrically through $\mathrm{x}$, which varies between 0 and $1 / 2$. Superior are the designs that offer small $R_{f}$ and small $R_{t h}$ at the same time. Such designs have $x$ values that are comparable with $1 / 2$. 
Alternatively, we can determine $\mathrm{H} / \mathrm{L}$ by minimizing $\mathrm{R}_{\text {th }}$ and then substituting the optimal $\mathrm{H} / \mathrm{L}$ into $R_{f}$. The result of this alternative is the left curve in Fig. 3. This curve is a numerical example

Table 1. Mesh accuracy test.

\begin{tabular}{ccc}
\hline Number of elements & $\Delta \mathrm{P}[\mathrm{Pa}]$ & Difference $(\%)$ \\
\hline 171,039 & 0.0333 & - \\
429,424 & 0.0324 & 2.61 \\
$1,424,572$ & 0.0317 & 2.24 \\
$6,515,363$ & 0.0313 & 1.15 \\
$7,571,873$ & 0.0313 & $<0.05$ \\
\hline
\end{tabular}

calculated by assuming $\rho=1000 \mathrm{~kg} / \mathrm{m}^{3}, v=10^{-6} \mathrm{~m}^{2} / \mathrm{s}, \dot{\mathrm{m}}=2 \mathrm{~kg} / \mathrm{s}, \mathrm{f}=0.025$, and $\mathrm{K}_{\mathrm{t}}=0.001$

$\mathrm{m}^{3} / \mathrm{kg}$. For turbulent flow in the core, the flow resistance varies in proportion with $(1-\mathrm{x})^{30 / 13} \mathrm{x}^{-}$ ${ }^{11 / 13}+(1-x)^{17 / 13} x^{-15 / 13}$. The overall thermal conductance varies monotonically with $(1-x)^{-5 / 13}$ $\mathrm{x}^{4 / 13}$. Figure 3 shows that the two approaches lead to the same conclusion: the better $\mathrm{R}_{\mathrm{f}}-\mathrm{R}_{\mathrm{th}}$ performance belongs with designs with $\mathrm{x} \cong 1 / 2$.

\section{Numerical method}

The pressure drop experienced by one stream $\dot{\mathrm{m}}_{1}$ in the counterflow parallel tubes solved analytically in the previous section can be solved numerically using the software COMSOL [23].Consider a fixed element volume of one stream $\dot{\mathrm{m}}_{1}$ in the heat exchanger with a longitudinal length $\mathrm{L}=1 \mathrm{~m}$ (one plenum + core), width $\mathrm{H}=1 \mathrm{~m}$ and depth $\mathrm{W}=0.1 \mathrm{~m}$, as shown in Fig. 4. The numberof parallel counterflow tubes in the element volume is $n=8$. Each tubehas the diameter $D$ $=0.7 \mathrm{~W}$. The fluid is water and the flow is three-dimensional, steady, fully developed and 
laminar at the inlet of the heat exchanger volume. The outside surface of the heat exchanger is insulated. The minimum overall pressure drop experienced by the stream $\dot{\mathrm{m}}_{1}$ can bedetermined by fixing the mass flow rate $(\dot{\mathrm{m}}=0.04 \mathrm{~kg} / \mathrm{s})$ at the inlet and varying $\mathrm{x}$ in the range $0.1-1 / 2$.

The entrance length for the flow in each pipe is defined as $\mathrm{L}_{\mathrm{e}}=0.06 \mathrm{Re} \mathrm{D}$. In the case of one tube (Fig. 6) the entrance length for the highest mass flowrate is 38 percent of the pipe length L, and this percentage decreases as we lower the mass flow rate or increase the number of tubes.

The numerical method consists of solving the mass, momentum and energy equations, in order to obtain the value of the outlet temperature for each stream. Non-isothermal flow type is used in COMSOL. The hot stream inlet temperature is $\mathrm{T}_{\mathrm{h}, \mathrm{in}}=330 \mathrm{~K}$ and the cold stream inlet temperature is $T_{c, i n}=295 \mathrm{~K}$. The tubes are assumed to be made of steel, and there is heat transfer continuity through the pipe walls.

The accuracy of the numerical solution depends on the grid refinement and mesh quality. We simulated the 3D flow with free tetrahedral mesh. In order to study the mesh quality, we selected several meshes for the case $\mathrm{x}=0.5$. Table 1 shows the accuracy test for the grid, starting with a coarse mesh proceeding to an extremely fine mesh. In the present numerical study, the results for this problem are grid independent and the meshing scheme is free tetrahedral. All the simulations in this problem are done with the mesh identified at the bottom of Table 1.

Figure 5 shows the effect of $\mathrm{x}$ on the overall pressure drop along the stream $\dot{\mathrm{m}}_{1}$. The pressure drop decreases as $\mathrm{x}$ increases, and the lowest pressure drop belongs to the design with $\mathrm{x}=0.5$. This behavior agrees with the analytical results from the preceding section, which is that for minimum pressure drop the best design is the one without a core.

\section{Effectiveness}

In order to find the effectiveness of the heat exchanger, consider a fixed element volume of 
two streams $\dot{\mathrm{m}}_{1}$ and $\dot{\mathrm{m}}_{2}$ in a heat exchanger with a longitudinal length $\mathrm{L}=2 \mathrm{~m}$, transversal dimension $\mathrm{H}=0.4 \mathrm{~m}$ and depth $\mathrm{W}=0.1 \mathrm{~m}$. As shown in Fig. 6 , the hot stream enters the volume at one end with temperature $\mathrm{T}_{\mathrm{h}, \mathrm{in}}=330 \mathrm{~K}$, and the cold stream enters the volume at the other end with temperature $T_{c, i n}=295 \mathrm{~K}$. Each stream flows through a tube before exiting the volume. The tube diameter remains $\mathrm{D}=0.7 \mathrm{~W}$. The flow is steady, fully developed and laminar at the inlet. The tubes are assumed to be made of steel with wall thickness $0.006 \mathrm{~m}$.

The effectiveness of the heat exchanger is defined as the ratio between the actual heat transfer to the maximum possible heat transfer,

$$
\varepsilon=\frac{\mathrm{q}}{\mathrm{q}_{\max }}=\frac{\mathrm{C}_{\mathrm{h}}\left(\mathrm{T}_{\mathrm{h}, \text { in }}-\mathrm{T}_{\mathrm{h}, \text { out }}\right)}{\mathrm{C}_{\min }\left(\mathrm{T}_{\mathrm{h}, \text { in }}-\mathrm{T}_{\mathrm{c}, \text { in }}\right)}=\frac{\mathrm{C}_{\mathrm{c}}\left(\mathrm{T}_{\mathrm{c}, \text { out }}-\mathrm{T}_{\mathrm{c}, \text { in }}\right)}{\mathrm{C}_{\min }\left(\mathrm{T}_{\mathrm{h}, \text { in }}-\mathrm{T}_{\mathrm{c}, \text { in }}\right)}
$$

where $\mathrm{C}_{\mathrm{h}}, \mathrm{C}_{\mathrm{c}}$, and $\mathrm{C}_{\min }$ are the hot, cold, and minimum heat capacity rates, respectively. The heat capacity rate ratio $\mathrm{C}_{\min } / \mathrm{C}_{\max }$ in this model is equal to 1 . The number of heat transfer units $\mathrm{N}_{\mathrm{tu}}$ is defined as the ratio between the overall thermal conductance and the minimum heat capacity rate,

$$
\mathrm{N}_{\mathrm{tu}}=\frac{\mathrm{UA}}{\mathrm{C}_{\min }}
$$

where $\mathrm{U}$ is the overall heat transfer coefficient and $\mathrm{A}$ is the heat transfer area. The relationship between the number of heat transfer units $\mathrm{N}_{\mathrm{tu}}$ and the effectiveness $\varepsilon$ for the heat exchanger is determined by varying the mass flow rate from $\dot{\mathrm{m}}=0.0003 \mathrm{~kg} / \mathrm{s}$ to $0.04 \mathrm{~kg} / \mathrm{s}$ at the inlet of both streams, while fixing the exit pressure and determining the outlet temperature of each stream. We started with the mass flow rate $\dot{\mathrm{m}}=0.04 \mathrm{~kg} / \mathrm{s}$ in order to maintain the flow laminar in the pipes with Reynolds numbers below 1500. Figure 6shows the effectiveness as a function of the number of heat transfer units.

In order to determine the effect of size on the results, we extended this study by changing the 
size of the heat exchanger to $\mathrm{L}=1 \mathrm{~m}$ and $\mathrm{H}=0.2 \mathrm{~m}$. Figure 6 shows the effectiveness vs $\mathrm{N}_{\mathrm{tu}}$ for the heat exchanger with smaller size. By comparing the results in Fig. 6, we see that changing the heat exchanger size has no effect on the results.

Next, we consider the same element volume but now each stream flows along two tubes and exits the volume as shown in Fig. 7. The inlet temperatures of the two streams, and the other assumptions, are the same as before. The relationship between the number of heat transfer units and the effectiveness can be determined in the same way, by varying the mass flow rate, this time fromm $=0.00075 \mathrm{~kg} / \mathrm{s}$ to $0.04 \mathrm{~kg} / \mathrm{s}$. Figure 7 shows the resulting function $\varepsilon\left(\mathrm{N}_{\mathrm{tu}}\right)$.

We extended this study by considering three tubes in cross flow in each plenum, Fig. 8. The inlet temperatures and the other assumptions are the same as before. The relation between the number of heat transfer units $\mathrm{N}_{\mathrm{tu}}$ and the effectiveness $\varepsilon$ is determined by varying the mass flow rate fromm $=0.004 \mathrm{~kg} / \mathrm{s}$ to $0.12 \mathrm{~kg} / \mathrm{s}$. Figure 8 shows the effectiveness versus the heat transfer units.

Figure 9shows a comparison between the $\left(\mathrm{N}_{\mathrm{tu}}\right)$ results obtained forthe three heat exchangermodels, labeled as single, double and triple relative to the number of tubes each stream passes through. The figure shows that all three heat exchanger models have the same $\varepsilon\left(\mathrm{N}_{\mathrm{tu}}\right)$ behavior. By comparing the numerical results with the analytical solution for counterflow and crossflow heat exchangers from Ref. [21], we find that the numerical results are in agreement with the known analytical curves for counterflow and crossflow. The numerical $\varepsilon\left(\mathrm{N}_{\mathrm{tu}}\right)$ curves are steeper than the analytical curves. By increasing the mass flow rate of each stream at the inlet of the heat exchanger, the velocity (Reynolds number) increases, which results in decreasing the effectiveness of the heat exchanger. This means that the laminar flow has higher effectiveness than turbulent flow. 


\section{Conclusions}

Correlations for laminar and turbulent flows were used to assess performance of a heat exchanger that consists of a core sandwiched between two plenums. The length of the core with respect to the length of the plenums is sought based on two objectives: low flow resistance and lowthermal resistance. The analysis showed that both the pressure drop and thermal resistance monotonically decrease with decreasing the core length.

In order to verify the use of correlations to evaluate the pressure drop, numerical simulations were first conducted for the fluid dynamics for several realistic plenum and core configurations. Numerical simulations of heat transfer were then conducted in order to obtain the $\mathrm{N}_{\mathrm{tu}}$ at various flow rates. The numerical simulation results for the heat transfer were found to be in good agreement with analytical solutions for counterflow and crossflow heat exchangers. The results indicate that for the configurations considered, the laminar flow has a higher effectiveness than that of the turbulent flow.

These results were obtained using (a) the same fluid on hot and cold sides of the heat exchanger, and (b) constant properties of hot and cold fluids. The overall flow and thermal resistance are the lowest when the core of the heat exchanger is absent, and each plenum occupies half of the available volume. When $\mathrm{N}_{\mathrm{tu}}<1$, the effectiveness vs number of heat transfer units curve is steeper than the classic curves for counterflow and crossflow. Increasing the number of tubes in the heat exchanger does not change the $\varepsilon\left(\mathrm{N}_{\mathrm{tu}}\right)$ behavior. These conclusions hold for fully developed laminar and turbulent flow through the core.

\section{Acknowledgements}

This work was performed for the project "Freeform Heat Exchangers for Binary Geothermal Power Plants" sponsored by the Geothermal Technologies Program, Office of Energy Efficiency 
and Renewable Energy, U.S. Department of Energy under contract DE-AC05-00OR22725, Oak Ridge National Laboratory, managed and operated by UT-Battelle, LLC. Mr. Alalaimi's work was supported by Kuwait University.

Notice: This submission was sponsored by a contractor of the United States Government under contract DE-AC05-00OR22725 with the United States Department of Energy. The United States Government retains, and the publisher, by accepting this submission for publication, acknowledges that the United States Government retains, a nonexclusive, paid-up, irrevocable, worldwide license to publish or reproduce the published form of this submission, or allow others to do so, for United States Government purposes.

\section{References}

1. W. M. Rohsenow, J. P. Hartnett and E. N. Ganić, Handbook of Heat Transfer Applications, $2^{\text {nd }}$ ed. McGraw-Hill, New York, 1985.

2. W. M. Kays and A. L. London, Compact Heat Exchangers, $3^{\text {rd }}$ ed., McGraw-Hill, 1984.

3. V. Ganapathy, Industrial Boilers and Heat Recovery Steam Generators: Design, Applications and Calculations, CRC Press, Boca Raton, FL, 2002.

4. A. G. Bloch, Heat Transfer in Steam Boiler Furnaces, Hemisphere, New York, 1998.

5. F. Zhang, B. Sunden, W. Zhang and G. Xie, Constructal parallel-flow and counterflow microchannel heat sinks with bifurcations, Numerical Heat Transfer, Part A, Vol. 68, 2015, pp. $1087-1105$.

6. J. Yang, S. Oh and W. Liu, Optimization of shell-and-tube heat exchangers using a general design approach motivated by constructal theory, International Journal of Heat and Mass Transfer, Vol. 77, 2014, pp. $1144-1154$.

7. Y. You, Y. Chen, M. Xie, X. Luo, L. Jiao and S. Huang, Numerical simulation and 
performance improvement for a small size shell-and-tube heat exchanger with trefoil-hold baffles, Applied Thermal Engineering, Vol. 89, 2015, pp. 220 - 228.

8. A. C. Caputo, P. M. Pelagagge and P. Salini, Heat exchanger design based on economic optimization, Applied Thermal Engineering, Vol. 28, 2008, pp. 1151 - 1159.

9. A. Singh, M. P. Maiya and S. S. Murthy, Effects of heat exchanger design on the performance of a solid state hydrogen storage device, International Journal of Hydrogen Energy, Vol. 40, 2015, pp. 9733 - 9746.

10. Jalaluddin, A. Miyara, K. Tsubaki, S. Inoue and K. Yoshida, Experimental study of several types of ground heat exchanger using a steel pile foundation, Renewable Energy, Vol 36, 2011, pp. $764-771$.

11. A. E. Bergles, R. L. Webb and G. H. Junkan, Energy conservation via heat transfer enhancement, Energy, Vol. 4, pp. 193-200, 1979.

12. R. L. Webb, Enhancement of single-phase Heat Transfer, Enhancement of Single-phase Heat Transfer, in S. Kakac, R. K. Shah, and A. E. Bergles ed., Wiley, New York, 1987.

13. T. A. Cowell, A general method for comparison of compact heat transfer surfaces, Journal of Heat Transfer, Vol. 112, 1990, pp. 288-294.

14. J. G. Soland, J. W. M. Mack and W M. Rohsenow, Performance ranking of plate-fin heat exchanger surfaces, Journal of Heat Transfer, Vol. 100, 1978, pp. 514-519.

15. V. D. Zimparov and N. L. Vulchanov, Performance evaluation criteria for enhanced heat transfer surfaces, Journal of Heat Transfer, Vol. 37, 1996, pp. 1807-1816.

16. A. Bejan, Maxwell's demons everywhere: evolving design as the arrow of time, Nature Scientific Reports, Vol. 4, No. 4017, 10 February 2014, DOI: 10.1038/srep04017. 
17. A. Bejan, The Physics of Life: The Evolution of Everything, St. Martin's Press, New York, 2016.

18. A. Bejan and S. Lorente, Design with Constructal Theory, Wiley, Hoboken, 2008.

19. A. Bejan, S. Lorente, B. S. Yilbas and A. Z. Sahin, The effect of size on efficiency: Power plants and vascular designs, International Journal of Heat and Mass Transfer, Vol. 54, 2011, pp. $1475-1481$.

20. A. Bejan, Convection Heat Transfer, $4^{\text {th }}$ ed., Wiley, Hoboken, 2013.

21. A. Bejan, Heat Transfer, Wiley, New York, 1993.

22. A. K. Pramanick, The Nature of Motive Force, Springer, New York, 2014, pp. 7-11.

23. http://www.comsol.com/.

\section{Appendix}

In order to estimate the overallheat transfer coefficients, the actual heat transfer pathways between the two streams must be considered for each of the plenum and core regions. In the plenum, the heat transfer pathway includes: (1) external convection of fluid 1, (2) conduction through the duct wall, and (3) and internal convection of fluid 2. In the core, the heat transfer pathway includes: (1) internal convection of fluid 1, (2) conduction across two wall thicknesses, and (3) and internal convection of fluid 2.

A1. Laminar flow correlations. The overall heat transfer coefficient in the plenum is given by:

$$
\frac{1}{\mathrm{~h}_{\mathrm{p}, \text { tot }}} \sim \frac{1}{\mathrm{~h}_{\mathrm{c}, \mathrm{l}}}+\frac{\mathrm{r}_{\text {in }}}{\mathrm{r}_{\text {out }}} \frac{1}{\mathrm{~h}_{\mathrm{p}}}+\frac{\Delta \mathrm{r}}{\mathrm{k}_{\text {metal }}}
$$

where $r_{\text {in }}=D / 2, r_{\text {out }}=\Delta r+D / 2$, and $\Delta r=r_{\text {out }}-r_{\text {in }}$. The order of magnitude of the external convection heat transfer coefficient, $\mathrm{h}_{\mathrm{p}}$, is estimated from the Nusselt number for a single tube in 
cross flow, cf. Eq. (7.100) in Ref. 14, where $h_{p} D / k_{f} \sim 0.6 \operatorname{Re}_{p}^{1 / 2}$ (if $\operatorname{Re}_{p}=U_{p} D / v>>1$, and $\operatorname{Pr}$ $\sim 1)$,

$$
\mathrm{h}_{\mathrm{p}} \sim \mathrm{C}_{2} \frac{\mathrm{k}_{\mathrm{f}}}{\mathrm{D}}\left(\mathrm{Re}_{\mathrm{p}}\right)^{\mathrm{m}}
$$

where $0.25 C_{2}\left(\operatorname{Re}_{\mathrm{p}}\right)^{\mathrm{m}}>1$ for $\mathrm{Re}>120$ (aligned tubes) and $\mathrm{Re}>50$ (staggered tubes). When the flow through the pipe is laminar and fully developed, then the in-duct Nusselt number is a constant of order 4 , and the internal heat transfer coefficient is of order:

$$
\mathrm{h}_{\mathrm{c}, 1} \sim 4 \frac{\mathrm{k}_{\mathrm{f}}}{\mathrm{D}}
$$

Table A1. Parameters C2 and m for Eq. (A2) for a single tube in crossflow [cf. Eq. (7.100) in Ref. 20].

\begin{tabular}{ccccc}
\hline Tubes & $\mathrm{Re}$ & $\mathrm{m}$ & $\mathrm{C}_{2}$ & $0.25 \mathrm{C}_{2}\left(\mathrm{Re}_{\mathrm{p}}\right)^{\mathrm{m}}$ \\
\hline Aligned & $1-10^{2}$ & 0.4 & 0.63 & $0.16-0.99$ \\
Aligned & $10^{2}-10^{3}$ & 0.5 & 0.36 & $0.90-2.85$ \\
Aligned & $10^{3}-210^{5}$ & 0.63 & 0.19 & $3.69-103.83$ \\
Staggered & $1-510^{2}$ & 0.4 & 0.85 & $0.21-2.55$ \\
Staggered & $510^{2}-10^{3}$ & 0.5 & 0.58 & $3.24-4.59$ \\
Staggered & $10^{3}-210^{5}$ & 0.6 & 0.21 & $3.31-79.58$ \\
\hline
\end{tabular}

Dividing Eqs. (A2) and (A3), we obtain 


$$
\frac{\mathrm{h}_{\mathrm{p}}}{\mathrm{h}_{\mathrm{c}, 1}} \sim 0.25 \mathrm{C}_{2}\left(\operatorname{Re}_{\mathrm{p}}\right)^{\mathrm{m}}
$$

andEq. (A1) becomes:

$$
\frac{\mathrm{h}_{\mathrm{c}, 1}}{\mathrm{~h}_{\mathrm{p}, \text { tot }}} \sim 1+\frac{\mathrm{r}_{\text {in }}}{\mathrm{r}_{\text {out }}} \frac{1}{0.25 \mathrm{C}_{2}\left(\mathrm{Re}_{\mathrm{p}}\right)^{\mathrm{m}}}+\mathrm{h}_{\mathrm{c}, 1} \frac{\Delta \mathrm{r}}{\mathrm{k}_{\text {metal }}}
$$

The total heat transfer coefficient in the core region is given by:

$$
\frac{\mathrm{h}_{\mathrm{c}, 1}}{\mathrm{~h}_{\mathrm{c}, 1, \text { tot }}} \sim 1+\frac{\mathrm{r}_{\text {in }}}{\mathrm{r}_{\text {out }}}+\mathrm{h}_{\mathrm{c}, 1} \frac{2 \Delta \mathrm{r}}{\mathrm{k}_{\text {metal }}}
$$

Thus, the ratio between the overall heat transfer coefficients for the plenumh $\mathrm{p}_{\text {,tot }}$ and the core $\mathrm{h}_{\mathrm{c}, 1, \text { tot }}$ becomes, after combining Eqs. (A5) and (A6),

$$
\frac{\mathrm{h}_{\mathrm{p}, \text { tot }}}{\mathrm{h}_{\mathrm{c}, 1, \text { tot }}} \sim \frac{1+\frac{\mathrm{r}_{\text {in }}}{\mathrm{r}_{\text {out }}}+\mathrm{h}_{\mathrm{c}, 1} \frac{2 \Delta \mathrm{r}}{\mathrm{k}_{\text {metal }}}}{1+\frac{\mathrm{r}_{\text {in }}}{\mathrm{r}_{\text {out }}} \frac{1}{0.15 \mathrm{Re}_{\mathrm{p}}^{1 / 2}}+\mathrm{h}_{\mathrm{c}, 1} \frac{\Delta \mathrm{r}}{\mathrm{k}_{\text {metal }}}}
$$

Table A2. Materials properties and typical dimensions (for water, $\mathrm{k}_{\mathrm{f}}=0.6 \mathrm{~W} / \mathrm{m}^{2} \mathrm{~K}$ ).

\begin{tabular}{llllll}
\hline Material/fluid & $\begin{array}{l}\mathrm{k}_{\text {metal }} \\
{\left[\mathrm{W} / \mathrm{m}^{2} \mathrm{~K}\right]}\end{array}$ & $\mathrm{k}_{\mathrm{f}} / \mathrm{k}_{\text {metal }}$ & $\begin{array}{c}\Delta \mathrm{r} \\
{[\mathrm{mm}]}\end{array}$ & $\begin{array}{l}\mathrm{D} \\
{[\mathrm{mm}]}\end{array}$ & $\frac{\Delta \mathrm{r}}{\mathrm{D}}\left(1+2 \frac{\Delta \mathrm{r}}{\mathrm{D}}\right)$ \\
\hline Aluminum & 200 & 0.003 & 0.3 & 10 & 0.032 \\
Carbon steel & 40 & 0.015 & 0.8 & 20 & 0.043 \\
Titanium & 5.8 & 0.103 & 0.1 & 10 & 0.01 \\
\hline
\end{tabular}

Thus, $\mathrm{h}_{\mathrm{p}, \text { tot }} / \mathrm{h}_{\mathrm{c}, 1, \text { tot }}>1$ when

$$
\frac{1}{0.25 \mathrm{C}_{2}\left(\mathrm{Re}_{\mathrm{p}}\right)^{\mathrm{m}}}<1+\mathrm{h}_{\mathrm{c}, 1} \frac{\Delta \mathrm{r}}{\mathrm{k}_{\text {metal }}} \frac{\mathrm{r}_{\text {out }}}{\mathrm{r}_{\text {in }}}
$$

Using Eq. (A3), dimensional relations for $r_{\text {in }}$ and $r_{\text {out }}$ as a function of pipe internal diameter, D, 
and pipe thickness, $\Delta \mathrm{r}$, and typical material properties and dimensions shown in Table A1, Eq. (A8) becomes:

$$
0.25 \mathrm{C}_{2}\left(\operatorname{Re}_{\mathrm{p}}\right)^{\mathrm{m}}>\frac{1}{1+4 \frac{\mathrm{k}_{\mathrm{f}}}{\mathrm{k}_{\text {metal }}} \frac{\Delta \mathrm{r}}{\mathrm{D}}\left(1+2 \frac{\Delta \mathrm{r}}{\mathrm{D}}\right)} \sim 1
$$

It is worth mentioning that condition (A9), for the materials, dimensions, and properties considered in Table A2, is almost identical to $0.25 \mathrm{C}_{2}\left(\operatorname{Re}_{\mathrm{p}}\right)^{\mathrm{m}}>1$, which can be derived by simply neglecting the heat conduction in both the plenum and core regions, respectively.

A2. Turbulent flow correlations. By replacing the internal laminar heat transfer coefficient with the corresponding turbulent flow correlation, relationships similar to(A1) and (A6) hold for the total heat transfer coefficients in the turbulent regime for the plenum and core regions,

$$
\begin{gathered}
\frac{\mathrm{h}_{\mathrm{c}, \mathrm{t}}}{\mathrm{h}_{\mathrm{p}, \text { tot }}} \sim 1+\frac{\mathrm{r}_{\text {in }}}{\mathrm{r}_{\text {out }}}\left(\frac{\mathrm{h}_{\mathrm{c}, \mathrm{t}}}{\mathrm{h}_{\mathrm{p}}}\right)+\mathrm{h}_{\mathrm{c}, \mathrm{t}} \frac{\Delta \mathrm{r}}{\mathrm{k}_{\text {metal }}} \\
\frac{\mathrm{h}_{\mathrm{c}, \mathrm{t}}}{\mathrm{h}_{\mathrm{c}, \mathrm{t}, \text { tot }}} \sim 1+\frac{\mathrm{r}_{\text {in }}}{\mathrm{r}_{\text {out }}}+\mathrm{h}_{\mathrm{c}, \mathrm{t}} \frac{2 \Delta \mathrm{r}}{\mathrm{k}_{\text {metal }}}
\end{gathered}
$$

If the flow through the tube is turbulent and fully developed, then according to Eq. (8.30) in Ref.

$20, h_{c, t} D / k_{f} \sim 0.023 \operatorname{Re}_{c}^{4 / 5}$ where $\operatorname{Re}_{c}=U_{c} D / v$, therefore

$$
\mathrm{h}_{\mathrm{c}, \mathrm{t}} \sim 0.023 \frac{\mathrm{k}_{\mathrm{f}}}{\mathrm{D}}\left(\operatorname{Re}_{\mathrm{c}}\right)^{4 / 5}
$$

Dividing Eqs. (A2) and (A12) we obtain

$$
\frac{h_{p}}{h_{c, t}} \sim 43.5 C_{2} \frac{\operatorname{Re}_{p}^{m}}{\operatorname{Re}_{c}^{4 / 5}}
$$

Because $\mathrm{U}_{\mathrm{p}}=\dot{\mathrm{m}}_{1} /(\rho \mathrm{xL})$ and $\mathrm{U}_{\mathrm{c}}=\left(\dot{\mathrm{m}}_{1} / \mathrm{n}\right) /\left(\rho \frac{\pi}{4} \mathrm{D}^{2}\right)$, we recognize 


$$
\frac{\mathrm{U}_{\mathrm{p}}}{\mathrm{U}_{\mathrm{c}}}=\frac{\pi}{4} \frac{\mathrm{H}}{\mathrm{xL}}, \quad \frac{\mathrm{Re}_{\mathrm{p}}}{\mathrm{Re}_{\mathrm{c}}}=\frac{\pi \mathrm{H}}{4 \mathrm{xL}}
$$

to rewrite Eq. (A13) as

$$
\frac{h_{p}}{h_{c, t}} \sim 36 C_{2} \operatorname{Re}_{p}^{m-4 / 5}\left(\frac{H}{x L}\right)^{4 / 5}
$$

The ratio between the overall heat transfer coefficients for the plenum and the core follows from combining (A10), (A11) and (A15),

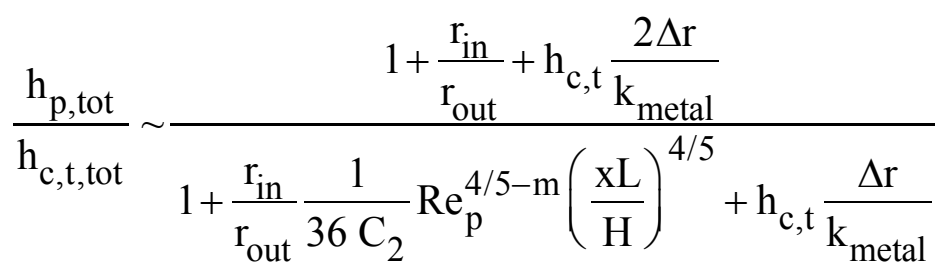

Using Eq. (A11) to relate $\operatorname{Re}_{c}$ to the $\mathrm{Re}_{\mathrm{p}}$ and data in Table $\mathrm{A} 2$, the ratio between the internal convection heat transfer coefficient and conduction through the metal becomes:

$$
\mathrm{h}_{\mathrm{c}, \mathrm{t}} \frac{\Delta \mathrm{r}}{\mathrm{k}_{\text {metal }}} \sim 0.023 \frac{\Delta \mathrm{r}}{\mathrm{D}} \frac{\mathrm{k}_{\mathrm{f}}}{\mathrm{k}_{\text {metal }}} \frac{1}{\left(\frac{\pi}{4} \frac{\mathrm{H}}{\mathrm{x} L}\right)^{4 / 5}} \operatorname{Re}_{\mathrm{p}}^{4 / 5} \sim(0.5 \div 5) * 10^{-5} \frac{1}{\left(\frac{\mathrm{H}}{\mathrm{x} \mathrm{L}}\right)^{4 / 5}} \operatorname{Re}_{\mathrm{p}}^{4 / 5}
$$

This relationship indicates that the conduction through the metal can be neglected when:

$$
\operatorname{Re}_{p}<\frac{H}{x L} \frac{\left(10^{5}\right)^{5 / 4}}{(0.5 \div 5)^{5 / 4}}
$$

The ratio between the overall heat transfer coefficients in the core and plenum follows from Eqs. (A16) and (A17), as: 


$$
\frac{\mathrm{h}_{\mathrm{c}, \mathrm{t}, \text { tot }}}{\mathrm{h}_{\mathrm{p}, \text { tot }}} \sim \frac{1+\left(\frac{\mathrm{xL}}{\mathrm{H}}\right)^{4 / 5}\left[\frac{1}{36 \mathrm{C}_{2}} \mathrm{Re}_{\mathrm{p}}^{4 / 5-\mathrm{m}}+(0.5 \div 5) * 10^{-5} \mathrm{Re}_{\mathrm{p}}^{4 / 5}\right]}{2+(0.5 \div 5) * 10^{-5} \mathrm{Re}_{\mathrm{p}}^{4 / 5}\left(\frac{\mathrm{xL}}{\mathrm{H}}\right)^{4 / 5}}
$$




\section{Figure captions}

Figure 1 Two streams in counterflow between two plenums in cross flow.

Figure 2 The heat exchanger design with lowest pressure drop.

Figure 3 Two objectives, simultaneously: the effect of $\mathrm{x}$ on the trade off between fluid flow resistance and thermal resistance.

Figure 4 The heat exchanger model used in the numerical solution to study the pressure drop.

Figure 5 The effect of varying $\mathrm{x}$ on the overall pressure drop experienced by the stream $\dot{\mathrm{m}}_{1}$.

Figure 6 The effectiveness as a function of the number of heat transfer units.

Figure 7 The effectiveness as a function of the number of heat transfer units for the heat exchanger model with each stream passes through two tubes.

Figure 8 The effectiveness versus the number of heat transfer units for the heat exchanger model with each stream passes through three tubes.

Figure 9 The effectiveness- $\mathrm{N}_{\mathrm{tu}}$ relations for the three heat exchanger configurations. 
Figure 2

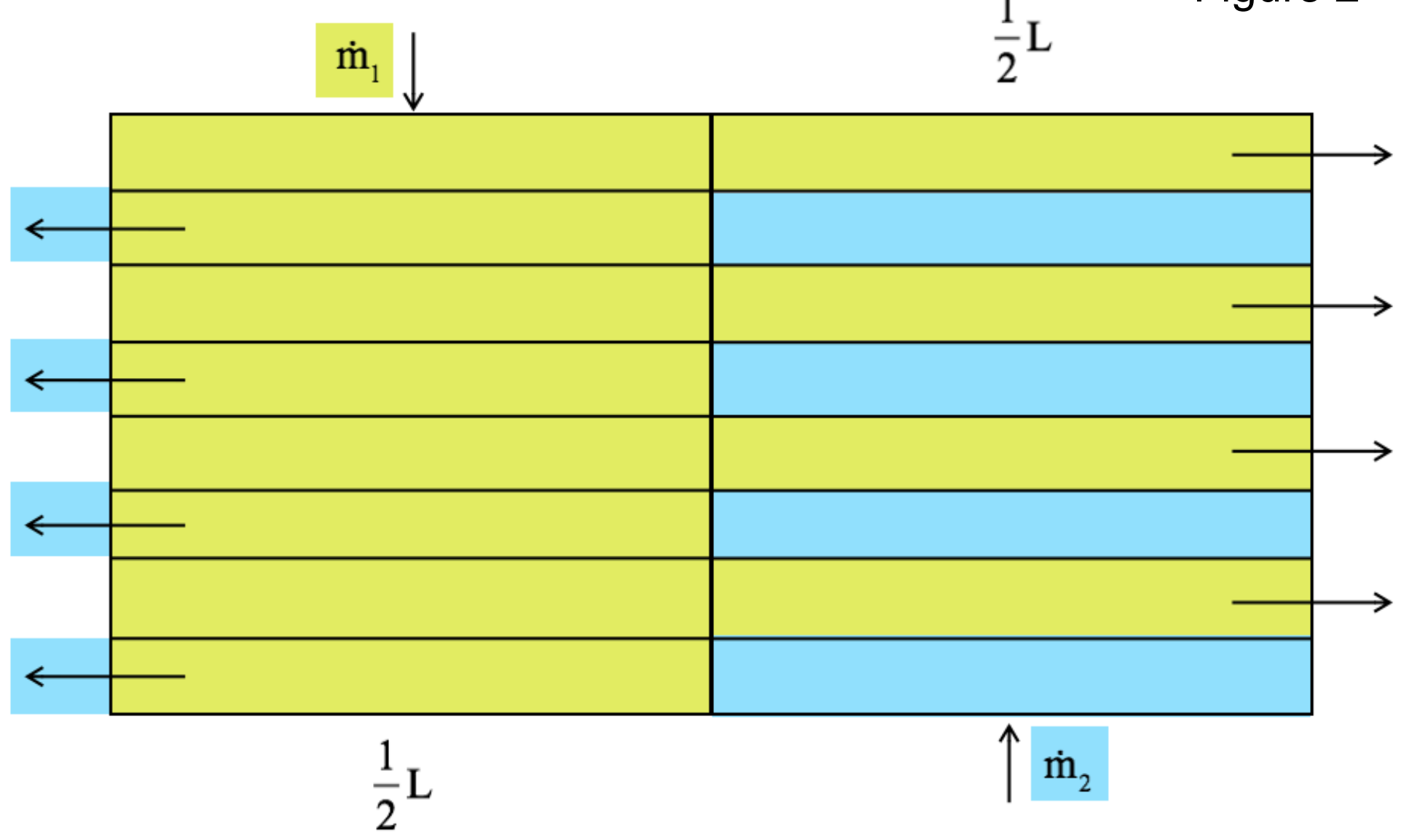




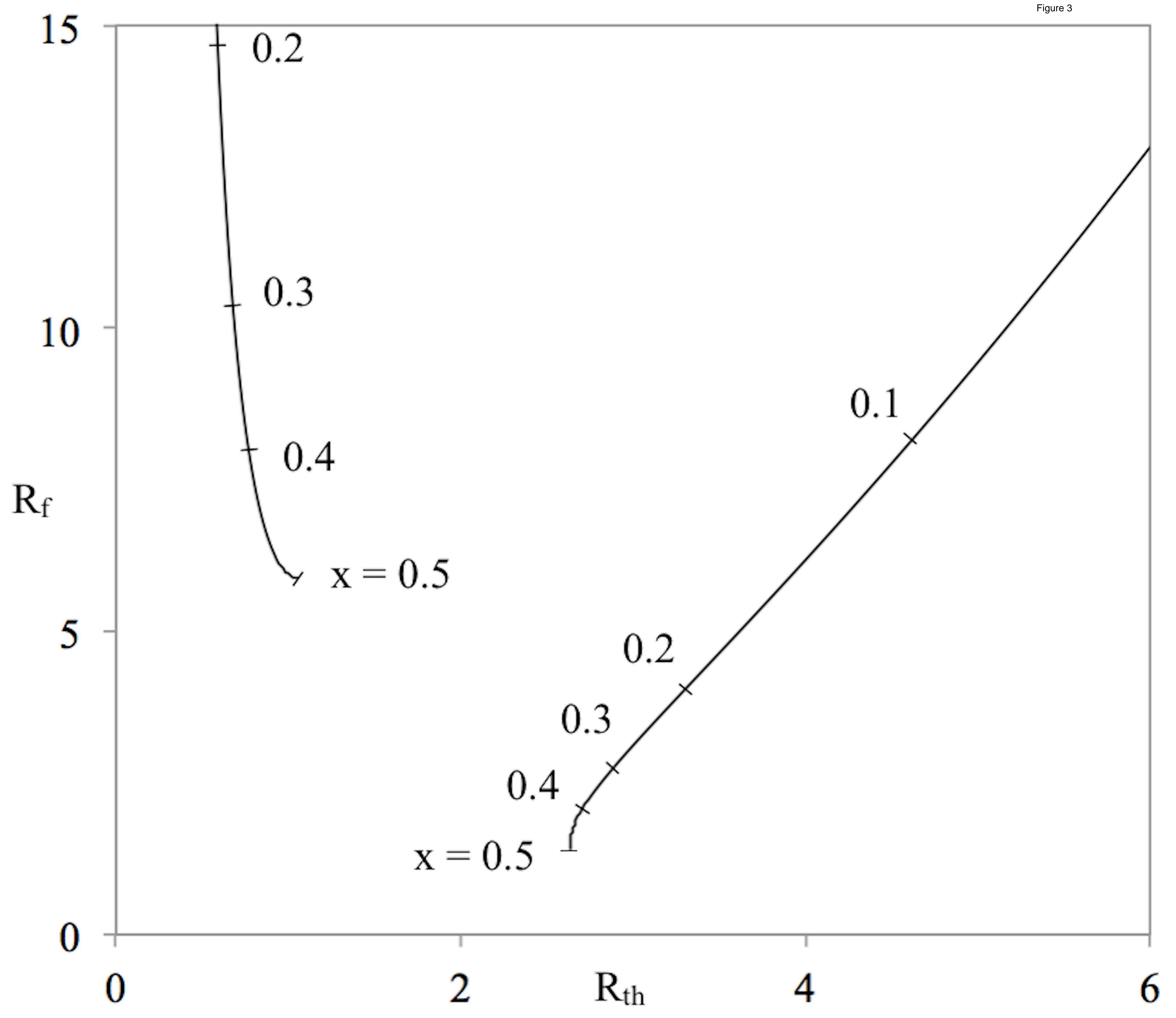


Figure 4

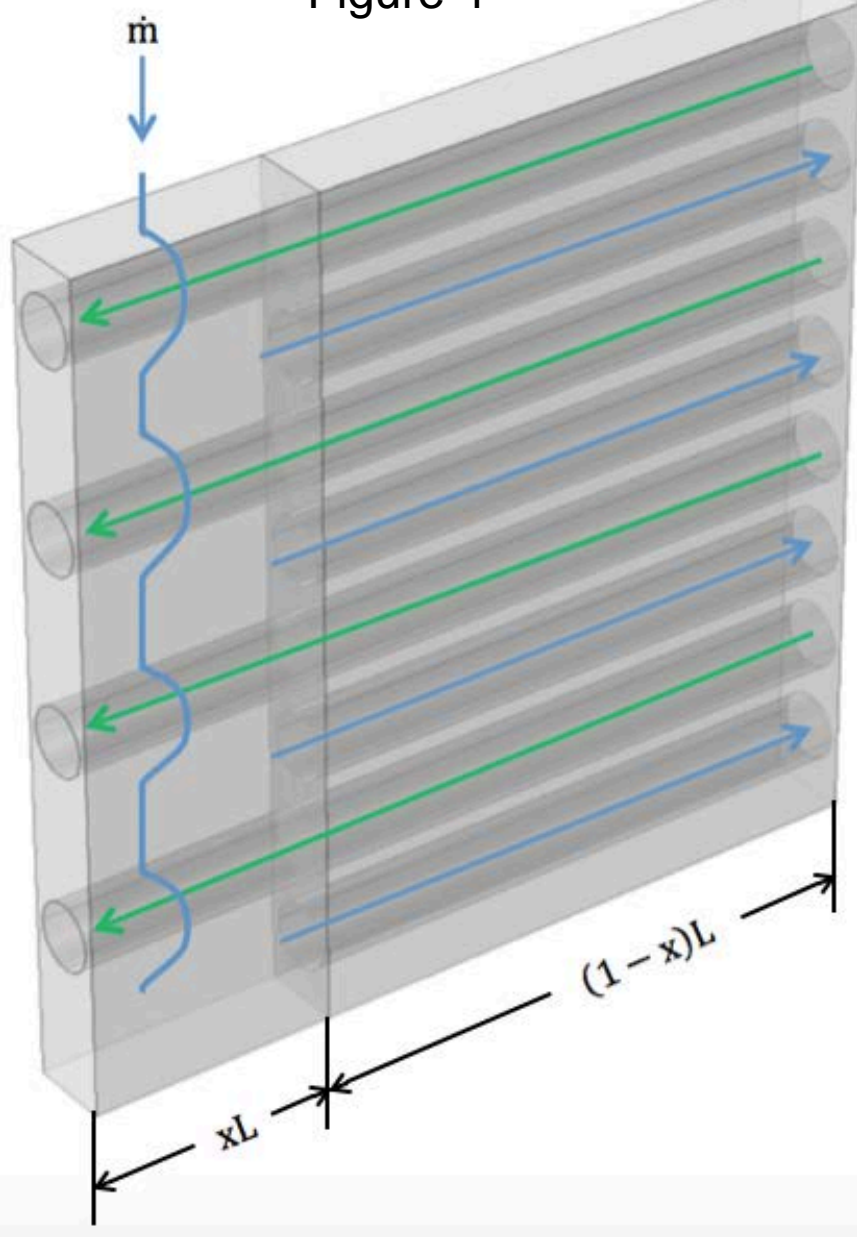




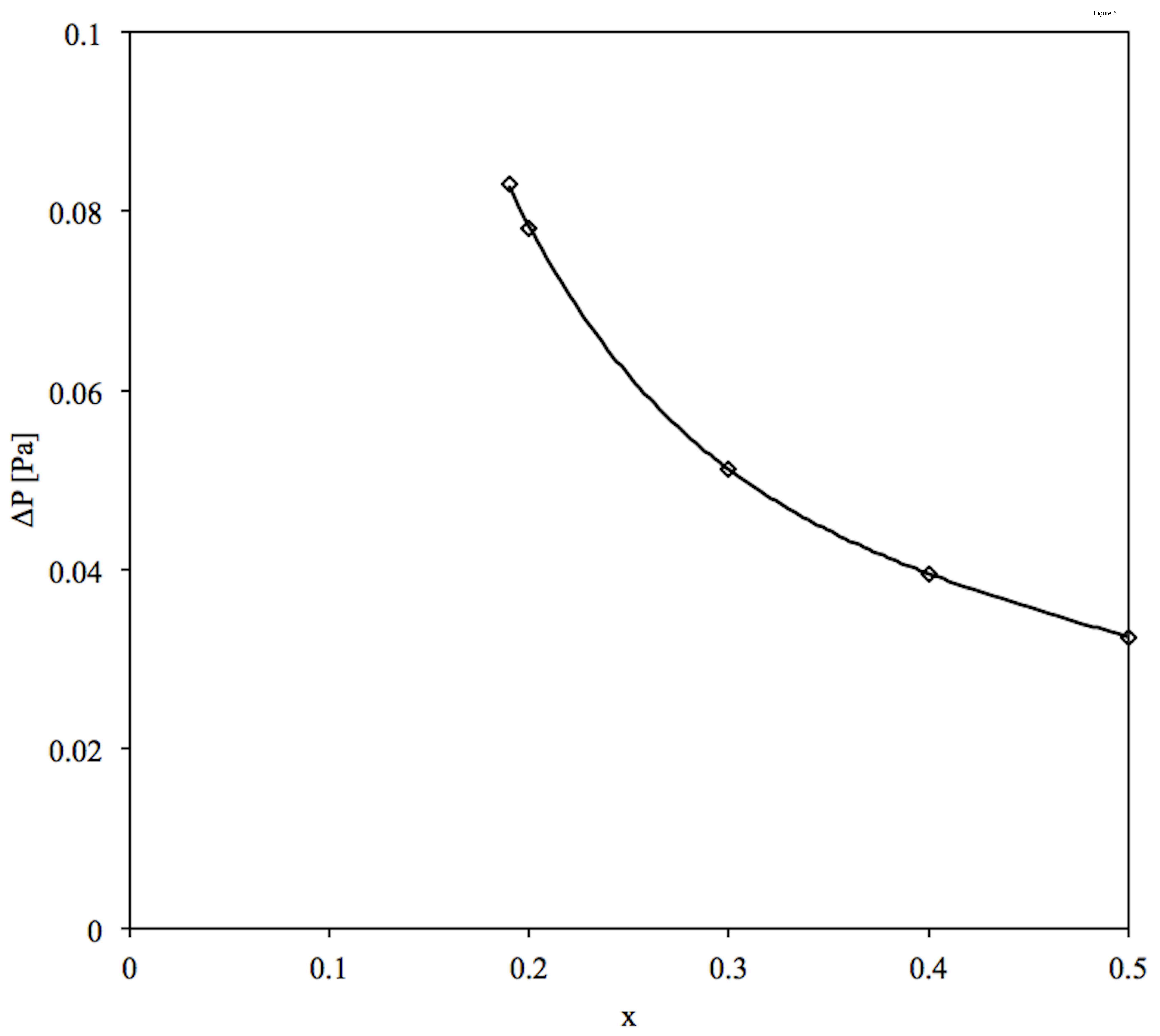


Figure 7

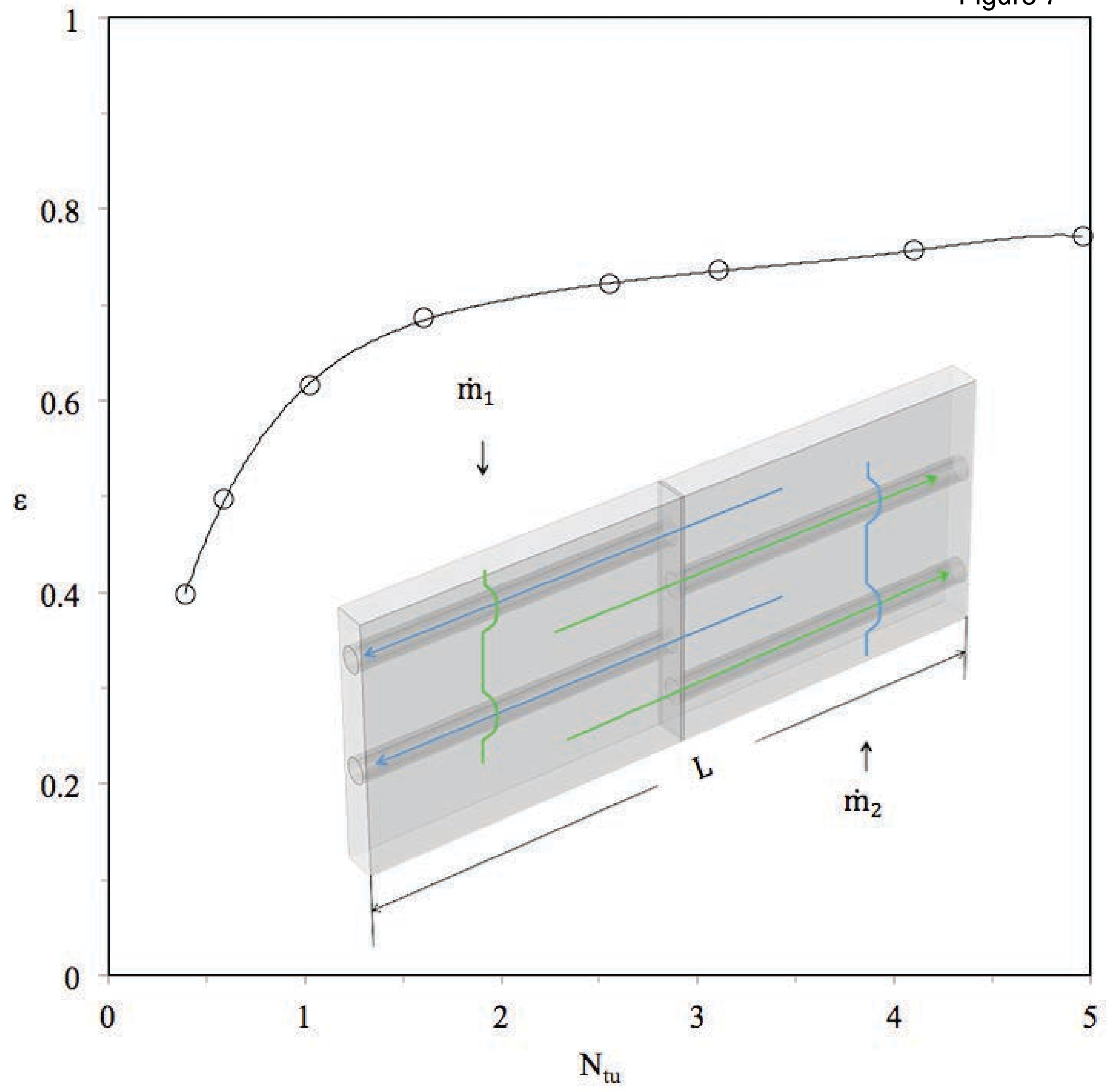




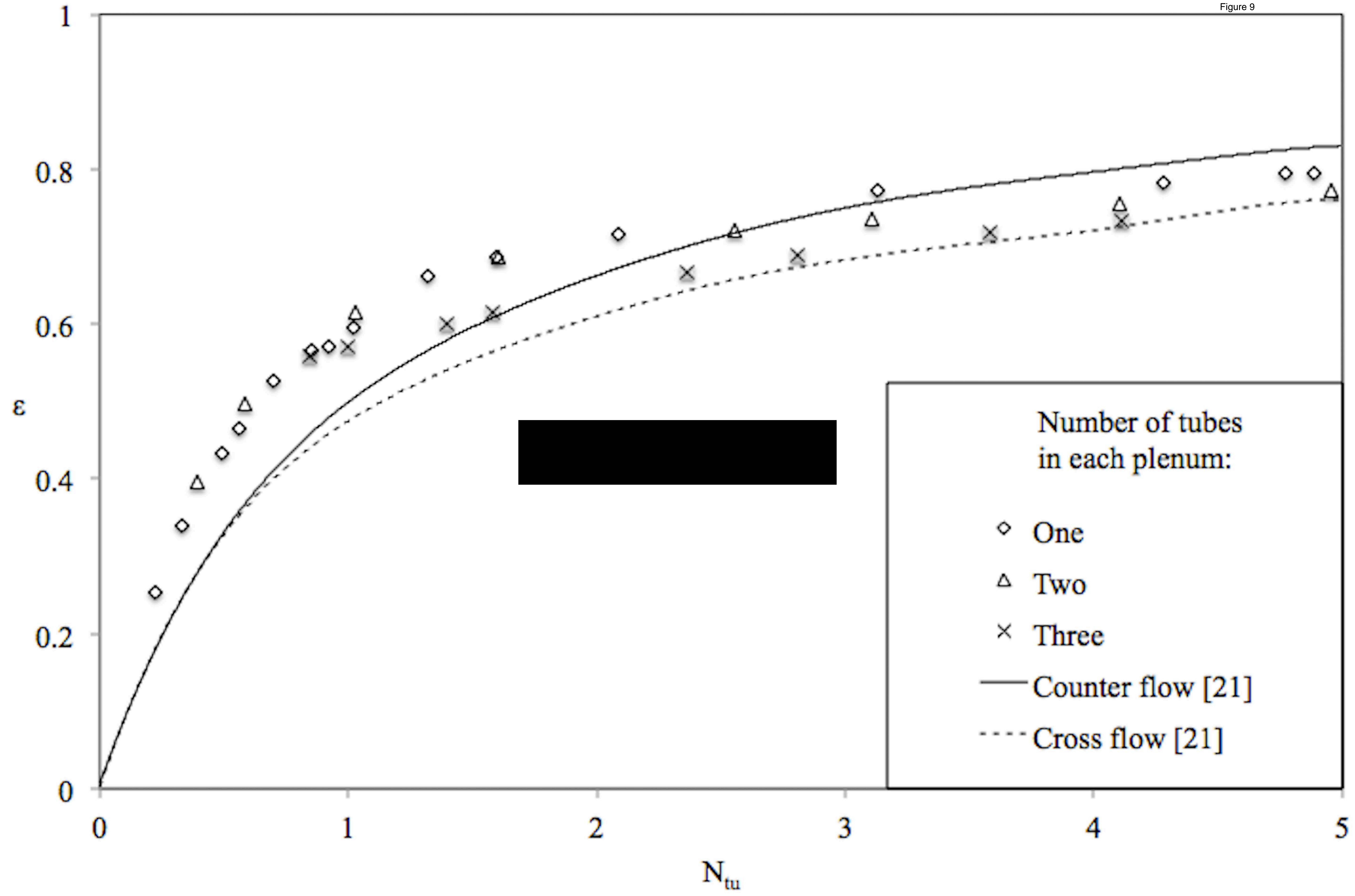




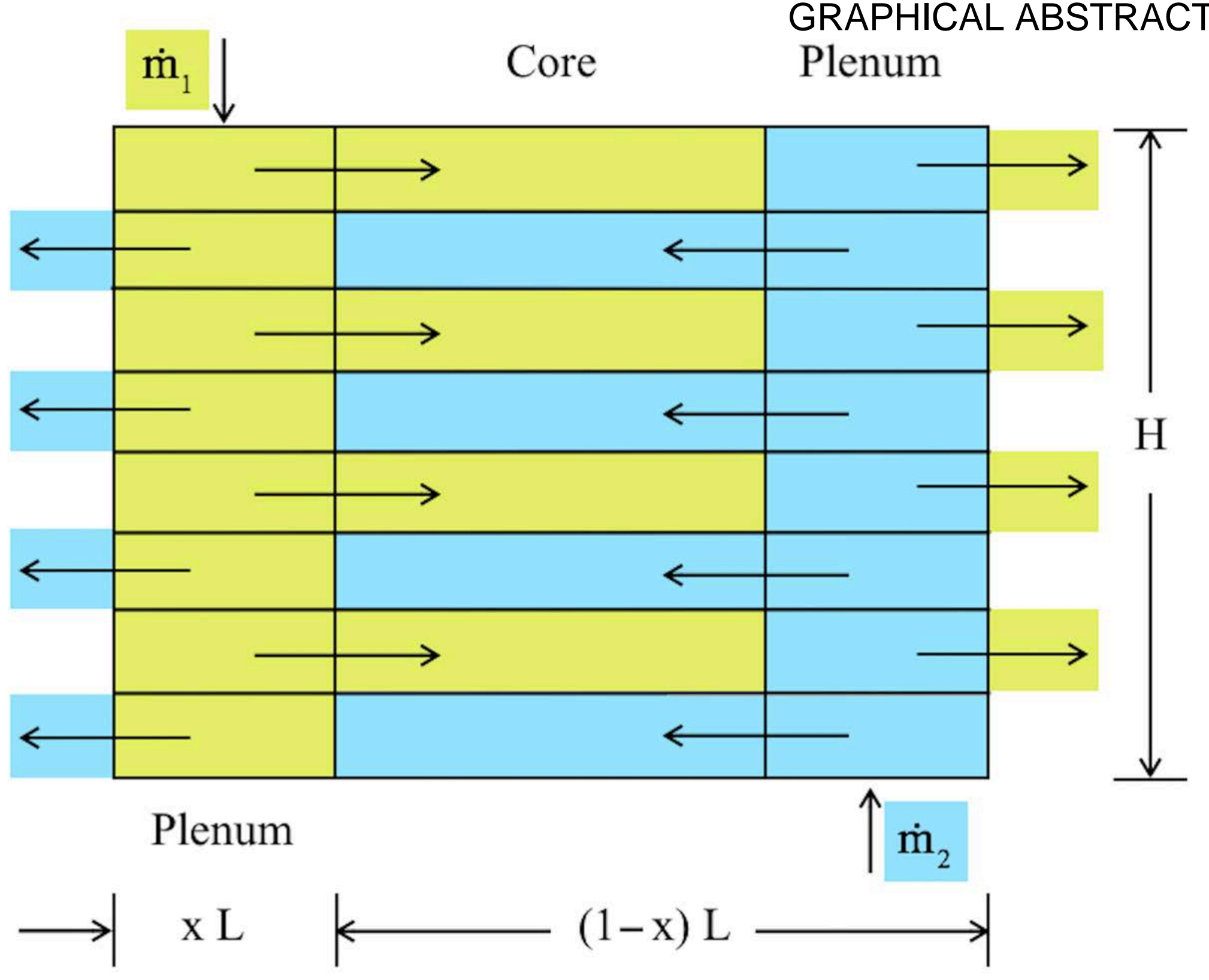

